\title{
B.C.C. 構造をむつ金属の融解熱および融解のエントロピー
}

\author{
竹 内栄* \\ J.Japan Inst.Metals, Vol.52,No.11(1988),pp.1039-1042
}

Latent Heat of Fusion and Entropy Change on Melting for Metals with B.C.C. Structure

Sakae Takeuchi*

The entropy change on melting $\Delta S$ for metals with the B.C.C. structure is about 0.75 of $\Delta S$ for metals with the F.C.C. structure. The mean distance between neighbouring atoms $\bar{R}$ observed experimentally in the liquid state of F.C.C. metals is very close to the atomic distance $R_{\mathrm{s}}$ in the solid state at the melting temperature, but $\bar{R}$ in the liquid state of B.C.C. metals is considerably larger than $R_{\mathrm{s}}$. The atomic distribution in liquid state of B.C.C. metals is shown to be in the random close packed arrangement same as that in the liquid state of F.C.C. metals. From this fact, it is supposed that B.C.C. metals transform to the liquid state through a transient stage of the F.C.C. structure on melting. The latent heat of transition from the B.C.C. structure to the transient stage reduces the thermal energy neccessary for fusion of B.C.C. metals. From this point, the latent heat of fusion and the entropy change on melting for B.C.C. metals are evaluated.

(Received May 6, 1988)

Keywords: transient stage of face-centered cubic structure, latent heat of fusion, entropy change on melting, liquid state of body centered cubic metals, structure change associating with melting

\section{I. 緒 論}

著者は先に金属結晶の融解の機構 ${ }^{(1)}$ を明らかにし, 融点 $T_{\mathrm{m}}$ は結晶の $0 \mathrm{~K} に$ に抢ける凝集エネルギーを一原子あたり $L_{0}$ とすれば

$$
\frac{9}{8} \frac{k T_{\mathrm{m}}}{L_{0}}=0.0344
$$

で与えられ,さらに f.c.c. および h.c.p. 構造をむつ金属 の融解熱 $\Delta E$ は

$$
\Delta E=1.173 N k T_{\mathrm{m}}=9.816 T_{\mathrm{m}}(\mathrm{J} / \mathrm{mol})^{\dagger}
$$

で記述され金属の融点 $T_{\mathrm{m}}$ に比例して増大するてとを示し た.しかしての式は b.c.c. 構造をむつ金属の融解熱には 適用されない. b.c.c. 構造をむつ金属ではこれより低い值 を与える.例えば同じような温度範囲融点をむつ $\mathrm{Ba}$ 上 $\mathrm{Mg}$ ，あるいは $\mathrm{Fe}$ と $\mathrm{Ni}$ の場合を比較すると

\begin{tabular}{crcccc}
\multicolumn{2}{c}{$T_{\mathrm{m}}(\mathrm{K})$} & $\Delta E(\mathrm{~kJ} / \mathrm{mol})$ & \multicolumn{2}{c}{$T_{\mathrm{m}}(\mathrm{K})$} & $\Delta E(\mathrm{~kJ} / \mathrm{mol})$ \\
$\mathrm{Ba}$ & 1000 & 7.66 & $\mathrm{Fe}$ & 1809 & 13.77 \\
$\mathrm{Mg}$ & 932 & 8.95 & $\mathrm{Ni}$ & 1726 & 17.49
\end{tabular}

の如くである.

金属液体の構造とその流動性に関する前報告 ${ }^{(2)}$ 亿示され た如く, Na，Kの如き b.c.c. 構造をむつ金属においても その溶融状態は $\mathrm{Al}, \mathrm{Pb}$ の如き f.c.c. 構造をもつ金属の液
体状態と同じように原子分布は無秩序ではあるが最密充填 型に近い配列の状態にありその中に多数の空孔が存在し， てれらの空孔は隣接原子と絶えずその位置を交換しながら 系内を容易に移動し，てれによって流動性を生ずる構造が 明らかになった. 空孔濃度 $\alpha(T)$ は, 融点では $\alpha\left(T_{\mathrm{m}}\right)=0.033$ で与えられ, 温度上昇と共に増大する。乙のような液体の 状態は熱力学的には $(1-\alpha) N$ 個の原子は振動運動の状態 に $\alpha N$ 個の原子は飛行運動の状態にあると考えるととが できる.

本報告では上記の見地に立って b.c.c. 構造をすつ金属 について融解の潜熱 $\Delta E$ および融解に伴うエントロピー 変化 $\Delta S$ を算出し, b.c.c. 構造をむつ金属の融解のエン トロピーおよび融解熱が f.c.c. 構造をむつ金属のそれより あ小さくなる根拠を明らかにする.

\section{II. 融解の潜熱 $\Delta E$}

I 節で述べたように b.c.c. 構造をもつ金属結晶が融解 し液体状態になるとf.c.c. 構造をむった金属の液体状態と 全く同じように原子分布は無秩序であるが最密充填型に近 い配列になる. しかし f.c.c. 金属の液体状態に打いては平均 の隣接原子間距離 $\bar{R}$ は融点近くの温度の結晶に扔ける原

* 東北大学名誉教授(Emeritus Professor of Tohoku University) $\uparrow \mathrm{kJ} \times 0.239=\mathrm{kcal}$. 
子間距離 $R$ と比較して殆んど変化がないか, 変化があっ ても非常に小さい，例えば $\mathrm{Cu}, \mathrm{Pb}$ を取っても見ると次の 如くである.

$\begin{array}{ccc} & R(\AA), \text { 結晶 } & \bar{R}(\AA)^{\dagger} \text {, 液体 } \\ \mathrm{Cu} & 2.556 & 2.565 \\ \mathrm{~Pb} & 2.501 & 2.536\end{array}$

しかし b.c.c. 金属が液体状態になると

$\begin{array}{lcc} & R(\AA), \text { 結晶 } & \bar{R}(\AA), \text { 液体 } \\ \mathrm{Na} & 3.7153 & 3.83 \\ \mathrm{~K} & 4.524 & 4.75\end{array}$

の如くであり, 平均の隣接原子間距離 $\bar{R}$ は結晶状態に掠 ける原子間距離 $R$ より相当増大している．液体状態に扝 ける $\bar{R}$ の值は実験的には構造因子 $S(Q)$ の測定加ら得ら れ，その值は原子が最密充塤の配列状態にあると仮定して 液体のモル体積から計算した值 ${ }^{(2)}$ 之非常によく一致する.

したがって b.c.c. 金属は融点では融解の機構(1) から推定 されるように b.c.c. 構造から f.c.c. 構造に遷移する過程 を経て無秩序であるが最密充填型の原子分布を取る液体状 態になると考えられよう。

それ故 $0 \mathrm{~K}$ に打いて b.c.c. 構造をむつ金属の疑集エネ ルギーをーN $L_{0}$ ，またての金属が f.c.c. 構造を取る場合 のそれを一 $N L_{0}^{\prime}$ とすれば, b.c.c 構造をすつ金属結晶の 全エネルギーは融点 $T_{\mathrm{m}}$ においては

$$
\begin{aligned}
E_{\mathrm{s}} & =-N L_{0}+3 N k T_{\mathrm{m}} \\
& =-N L_{0}^{\prime}+N\left(L_{0}^{\prime}-L_{0}\right)+3 N k T_{\mathrm{m}}
\end{aligned}
$$

と書くことができる.

次に融点 $T_{\mathrm{m}}$ における液体状態のエネルギー $E_{\mathrm{L}}$ を求め る. 前述の如く液体状態においては原子分布は無秩序であ るが最密充填に近い配列をしており，そのような原子配列 の中に空孔が存在している．乙れらの空孔に隣接する原子 は，規則配列をしている結晶の場合とは異なり，非常に容 易に空孔の中心へ移動するととができ，したがって空孔は 殆んど自由に隣接原子と位置を交換しながら液体内を移動 している.

てのような液体の中において任意の 1 つの原子 $i$ 亿対し て実質的に相互作用を及ぼしている隣接原子の平均数を $\bar{Z}(1-\alpha)$ とする． $\alpha$ は融点 $T_{\mathrm{m}}$ に打ける液体中の空孔濃度 で $\alpha\left(T_{\mathrm{m}}\right)=0.033$ である. これらの隣接原子は原子 $i$ の周 りの球殼内に分布している. したがって $\bar{Z}(R)$ を 1 つの原 子から半径 $R$ の球面上に見出される原子数とすると次の 関係が成立つ。

$$
\sum_{R} Z(R)=\bar{Z}(1-\alpha)
$$

1 つの原子とそれから距離 $R$ 亿存在する原子との間の 相互作用のポテンシャルを $u(R)$ とし，ポテンシャルの極 小位置までの距離を $R_{0}$ とすれば, 1 つの原子から $R$ の距 離に他の原子が見出される確率 $Z(R) / \bar{Z}(1-\alpha)$ は

$$
\dagger \AA=10^{-8} \mathrm{~cm}=0.1 \mathrm{~nm} \text {. }
$$

$$
\frac{Z(R)}{\bar{Z}(1-\alpha)}=\frac{Z\left(R_{0}\right)}{\bar{Z}(1-\alpha)} \exp \left[-\frac{u(R)-u\left(R_{0}\right)}{k T}\right]
$$

で与えられる.ここで $Z\left(R_{0}\right) / \bar{Z}(1-\alpha)$ は $u(R)$ が具体的 な形で与えら机ると

$$
\int_{-\infty}^{\infty} 4 \pi \frac{Z(R)}{\bar{Z}(1-\alpha)}\left(\frac{R}{R_{0}}\right)^{2} \mathrm{~d}\left(\frac{R}{R_{0}}\right)=1
$$

加計算される.

液体状態においては各原子が隣接する原子との相互作用 によるポテンシャル $u(R)$ は必ずしも等しくはならない故 平均の 2 体ポテンシャル $\overline{u(R)}$ を用いる必要がある. $N(1-\alpha)$ 個の原子はその周囲の隣接原子との相互作用によ るポテンシャル $1 / 2 \bar{Z}(1-\alpha) \cdot \overline{u(R)}$ の下で振動運動の状 態にあり, $\alpha N$ 個の原子はその周囲の原子の作るポテンシャ ルの場の中で隣接する空孔へ向けての 1 次元的な飛行運動 の状態にある。それ故液体状態での全エネルギー ${ }^{(1)}$ は

$$
\begin{aligned}
E_{\mathrm{L}}= & N(1-\alpha) \frac{\bar{Z}(1-\alpha)}{2} \overline{u(R)}+\frac{2}{3} N(1-\alpha) k T_{\mathrm{m}} \\
& +\alpha N \frac{\bar{Z}(1-\alpha)}{2} \overline{u(R)}+\frac{1}{2} \alpha N k T_{\mathrm{m}} \\
= & N(1-\alpha) \frac{\bar{Z}}{2} \overline{u(R)}+\left(\frac{3}{2}-\alpha\right) N k T_{\mathrm{m}} .
\end{aligned}
$$

前に述べた如く b.c.c. 構造の金属に対してもその液体状 態ではf.c.c. 構造の金属の場合のように無秩序ではあるが 最密充填に近い原子分布を取る故 $u(R)$ 亿対して Morse のポテンシャルを用いると $\overline{u(R)}$ は

$$
\begin{aligned}
\overline{u(R)}= & -\frac{2}{Z_{0}} L_{0}^{\prime}+\frac{2}{Z_{0}} L_{0}^{\prime}\left(a R_{0}\right)^{2} \\
& \times\left\{\overline{\left(\frac{R-R_{0}}{R_{0}}\right)^{2}-\left(a R_{0}\right)\left(\overline{\left.\frac{R-R_{0}}{R_{0}}\right)^{3}}\right\}}\right.
\end{aligned}
$$

で与えられるが，乙てで $Z_{0}=\bar{Z}=12$ と取ってよい.し たがって融解熱 $\Delta E$ は次式のように書かれる.

$$
\begin{aligned}
& \Delta E=E_{\mathrm{L}}-E_{\mathrm{S}} \\
& =-N(1-\alpha) L_{0}^{\prime}+N(1-\alpha) L_{0}^{\prime}\left(a R_{0}\right)^{2}\left\{\overline{\left(\frac{R-R_{0}}{R_{0}}\right)^{2}}\right. \\
& \left.-\left(a R_{0}\right) \overline{\left(\frac{R-R_{0}}{R_{0}}\right)^{3}}\right\}+N L_{0}^{\prime}-N\left(L_{0}^{\prime}-L_{0}\right) \\
& -\left(\frac{3}{2}+\alpha\right) N k T_{\mathrm{m}} \\
& =\alpha N L_{0}^{\prime}+N(1-\alpha) L_{0}^{\prime}\left(a R_{0}\right)^{2}\left\{\overline{\left(\frac{R-R_{0}}{R_{0}}\right)^{2}}\right. \\
& \left.-\left(a R_{0}\right) \overline{\left(\frac{R-R_{0}}{R_{0}}\right)^{3}}\right\}-\left(\frac{3}{2}+\alpha\right) N k T_{\mathrm{m}}^{\prime} \\
& +\left(\frac{3}{2}+\alpha\right) N k\left(T_{\mathrm{m}}^{\prime}-T_{\mathrm{m}}\right)-N\left(L_{0}^{\prime}-L_{0}\right)
\end{aligned}
$$

ここで $T_{\mathrm{m}}^{\prime}$ は金属が f.c.c. 構造の状態にある時の融点であ る.しかるに

$$
\frac{9}{8} \frac{k T_{\mathrm{m}}}{L_{0}}=\frac{9}{8} \frac{k T_{0}^{\prime}}{L_{0}^{\prime}}=0.0344
$$

であるから, b.c.c. から f.c.c. 構造への相変態の潜熱に関 する係数 $\beta$ を導入し

$$
L_{0}^{\prime}=(1+\beta) L_{0}
$$

と取ると

$$
T_{\mathrm{m}}^{\prime}=(1+\beta) T_{\mathrm{m}}
$$


が成り立つ.かくして $\Delta E$ は ことに

$$
\Delta E=\Delta E^{\prime}+\left(\frac{3}{2}+\alpha\right) \beta N k T_{\mathrm{m}}-\beta N L_{0}
$$

$$
\begin{aligned}
\Delta E^{\prime}= & \alpha N L_{0}^{\prime}+N(1-\alpha) L_{0}^{\prime}\left(\alpha R_{0}\right)^{2}\left\{\overline{\left(\frac{R-R_{0}}{R_{0}}\right)^{2}}\right. \\
& -\left(a R_{0}\right) \overline{\left.\left(\frac{R-R_{0}}{R_{0}}\right)^{3}\right\}}-\left(\frac{3}{2}+\alpha\right) N k T_{\mathrm{m}}^{\prime}
\end{aligned}
$$

$\Delta E^{\prime}$ は前報告(1)で示したようにf.c.c. 構造をすった金属 の融解熱倍対する式である. それ故 $\alpha=0.033$ を用いると

$$
\begin{aligned}
& \Delta E^{\prime}=1.173 N k T_{\mathrm{m}}^{\prime} \\
& a R_{0}=3.847
\end{aligned}
$$

と取られる. $a$ の値は液体の圧縮率から計算される係数で $R_{0}$ は隣接原子間の平均距離である. 式 (9)加ら式(10)の $\Delta E^{\prime}$ を計算するには平均值 $\left\{\overline{\left.\left(R-R_{0}\right) / R_{0}\right\}^{2}}\right.$ 扤よび $\{\overline{(R-}$ $\overline{\left.\left.R_{0}\right) / R_{0}\right\}^{3}}$ の值を求めなりればならない。それれには式 $(2)$ の $u(R)$ Morse のポテンシャルを代入して分布関数

$$
\begin{aligned}
\frac{Z(R)}{\bar{Z}(1-\alpha)}= & \frac{Z\left(R_{0}\right)}{\bar{Z}(1-\alpha)} \exp \left[-\frac{2}{Z_{0}} \frac{L_{0}^{\prime}}{k T_{\mathrm{m}}^{\prime}}\left(a R_{0}\right)^{2}\right. \\
& \left.\times\left\{\left(\frac{R-R_{0}}{R_{0}}\right)^{2}-\left(a R_{0}\right)\left(\frac{R-R_{0}}{R_{0}}\right)^{3}\right\}\right]
\end{aligned}
$$

が得られ，乙れを式( 3 )に代入し $(6)$ ，(11) 扔よび $Z_{0}$ =12 代入すると

$$
\frac{Z\left(R_{0}\right)}{\bar{Z}(1-\alpha)}=0.37415
$$

が得られ，乙れを用いて式(12)から次の平均值を計算する ことができ，

$$
\begin{aligned}
& \overline{\left(\frac{R-R_{0}}{R_{0}}\right)^{2}}=0.0079136 \\
& \overline{\left(\frac{R-R_{0}}{R_{0}}\right)^{3}}=0.0011534
\end{aligned}
$$

乙れを式(9)に代入すると式(10)が得られる. 式( 8 )と(10) および $(6)$ からの $L_{0}=32.7035 k T_{\mathrm{m}}$ を用いると

$$
\begin{aligned}
\Delta E & =1.173 N k T_{\mathrm{m}}^{\prime}+\beta\left\{\left(\frac{3}{2}+\alpha\right)-32.7035\right\} N k T_{\mathrm{m}} \\
& =1.173 N k T_{\mathrm{m}}+\beta\{1.173+1.533-32.7035\} N k T_{\mathrm{m}}
\end{aligned}
$$

$\beta$ は $(7),\left(7^{\prime}\right)$ から b.c.c. $\rightarrow$ f.c.c. への相変態の潜熱に関 する係数で

$$
\beta=\frac{L_{0}^{\prime}-L_{0}}{L_{0}}=\frac{T_{\mathrm{m}}^{\prime}-T_{\mathrm{m}}}{T_{\mathrm{m}}}
$$

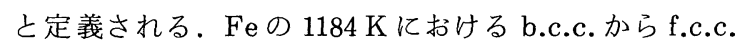
への変態熱は $1.05 \mathrm{~kJ} / \mathrm{mol}$ 程度であり,したがって $\beta$ は 0.002 程度が考えられるが，しかし前述のように b.c.c. 金 属の溶融状態は, 融解に際して b.c.c. から f.c.c. 構造へ の遷移過程を経て無秩序であるが最密充填近い原子分布 になると考えるてとができるが，安定相としての f.c.c. 構 造が融解敒して察際䅉測されている訳ではなく, 遷移 状態として仮定されるのである. そ机故 $\left(L_{0}^{\prime}-L_{0}\right) / L_{0}$ の 值は 0.002 より当然大きくなると考元れ，

$$
\beta \leq 0.01
$$

と考えてよい，とこでは

$$
\beta=0.0096
$$

と取って計算を進める。したがって式(15)は

$$
\begin{aligned}
\Delta E & =(1.173-0.2879) N k T_{\mathrm{m}} \\
& =0.8851 N k T_{\mathrm{m}} \\
& =7.4067 T_{\mathrm{m}}(\mathrm{J} / \mathrm{mol})
\end{aligned}
$$

が得られる. Fig.1にアルカリ金属, アルカリ土類金属, その他 $\mathrm{Tl}$ ，および $\mathrm{Fe}$ の如き b.c.c. 金属の融解熱 $\Delta E$ の 測定値が融点の実測值 $T_{\mathrm{m}}$ に対して図示してあり式(17') はてれらの測定値とよい一致を示している.

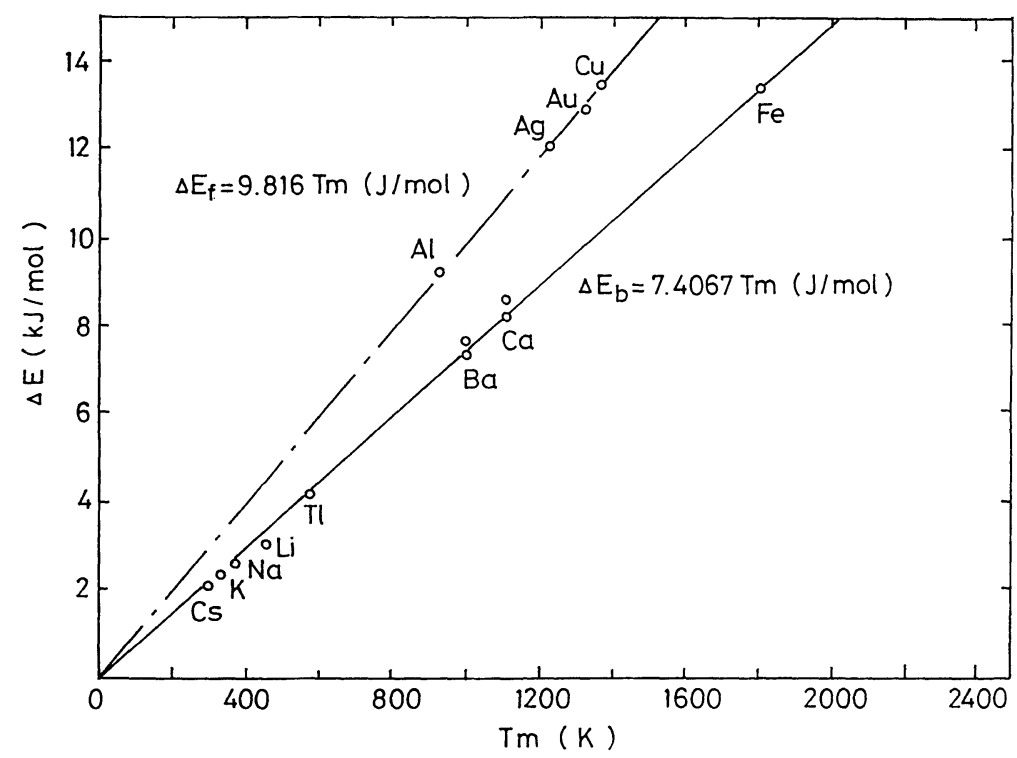

Fig.1 Latent heat of fusion $\Delta E$ as a function of the melting temperature $T_{\mathrm{m}}$ for metals with the f.c.c. and b.c.c. structures. 


\section{III. 融解に伴うエントロピー変化 $\Delta S$}

融解に際してのエントロピー変化は熱的エントロピー変 化 $\Delta S_{1}$ とポテンシャルエネルギー準位の多重度に起因す るエントロピー変化 $\Delta S_{2}$ の和から成り立っていると考え られる。

融解に際して結晶状態の熱的エントロピーは式( 3 )にお ける $N\left(L_{0}^{\prime}-L_{0}\right)$ は変態熱として作用するから

$$
\begin{aligned}
\frac{N\left(L_{0}^{\prime}-L_{0}\right)}{T_{\mathrm{m}}}+3 N k & =\beta \frac{N L_{0}}{T_{\mathrm{m}}}+3 N k \\
& =32.7035 \beta N k+3 N k .
\end{aligned}
$$

液体状態に拈いては $N(1-\alpha)$ 個の原子が振動運動の状 態に， $\alpha N$ 個の原子が 1 次元的な飛行運動の状態にあるか ら $T_{\mathrm{m}}$ における液体の熱的エントロピーは

$$
3 N(1-\alpha) k+\alpha N k=(3-2 \alpha) N k
$$

で与えられ，したがって融解に際しての熱的エントロピー の変化 $\Delta S_{1}$ は $(18),\left(18^{\prime}\right)$ から

$$
\begin{aligned}
\Delta S_{1} & =(3-2 \alpha) N k-3 N k-32.7035 \beta N k \\
& =-2 \alpha N k-32.7035 \beta N k
\end{aligned}
$$

次に液体および結晶状態におけるポテンシャル・エネル ギー準位の多重度をそれぞれ $W_{\mathrm{L}}$ および $W_{\mathrm{S}}$ で表わすと， エントロピー変化 $\Delta S_{2}$ は

$$
\Delta S_{2}=k \log _{\mathrm{e}} W_{\mathrm{L}}-k \log _{\mathrm{e}} \bar{W}_{\mathrm{S}}
$$

で与えられる.しかし結晶状態では各原子は同一のポテン シャル・エネルギー状態にあると考えられるから $W_{\mathrm{S}}=1$ と取ってよい，それ故

$$
\Delta S_{2}=k \log _{\mathrm{e}} W_{\mathrm{L}} \text {. }
$$

液体状態においては無秩序な原子配列の状態にあるから， ポテンシャル・エネルギー $\varepsilon_{1}, \varepsilon_{2}, \cdots \varepsilon_{i} \cdots$ をむつ原子数を それぞれ $n_{1}, n_{2}, \cdots n_{i} \cdots$ とすると平均のポテンシャル・ エネルギー $\bar{\varepsilon}$ は

$$
N \bar{\varepsilon}=\sum_{i} n_{i} \varepsilon_{i}
$$

で与えられるから， $\bar{W}_{\mathrm{L}}$ は

しかるに

$$
W_{\mathrm{L}}=\frac{N !}{\pi n_{i} !}
$$

$$
\frac{n_{i}}{N}=\frac{Z\left(R_{i}\right)}{\bar{Z}(1-\alpha)}
$$

とおくことができる故 ${ }^{(1)}$

$$
\begin{aligned}
\Delta S_{2} & =k \log _{\mathrm{e}} W_{\mathrm{L}} \\
& =-N k \sum_{i} \frac{n_{i}}{N} \cdot \log _{\mathrm{e}} \frac{n_{i}}{N} \\
& =-N k \sum_{i} \frac{Z\left(R_{i}\right)}{\bar{Z}(1-\alpha)} \cdot \log _{\mathrm{e}} \frac{Z\left(R_{i}\right)}{\bar{Z}(1-\alpha)}
\end{aligned}
$$

積分形にして式(12)を用いると

$$
\begin{aligned}
\Delta S_{2} & -N k \int_{-\infty}^{\infty} 4 \pi\left(\frac{R}{R_{0}}\right)^{2} \frac{Z(R)}{\bar{Z}(1-\alpha)} \log _{\mathrm{e}} \frac{Z(R)}{\bar{Z}(1-\alpha)} d\left(\frac{R}{R_{0}}\right) \\
= & -N k \log _{\mathrm{e}} \frac{Z\left(R_{0}\right)}{\bar{Z}(1-\alpha)} \\
& +\frac{2 L_{0}^{\prime}}{Z_{0} k T_{\mathrm{m}}}\left(a R_{0}\right)^{2}\left\{\overline{\left(\frac{R-R_{0}}{R_{0}}\right)^{2}}-\left(a R_{0}\right) \overline{\left(\frac{R-R_{0}}{R_{0}}\right)^{3}}\right\} N k
\end{aligned}
$$$$
\text { 式(19)の } \Delta S_{1} \text { を用いると }
$$$$
\Delta S=\Delta S_{1}+\Delta S_{2}
$$

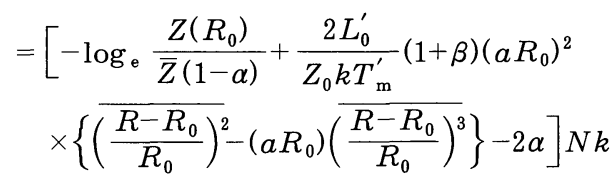

$-32.7053 \beta N k$

$\beta \ll 1$ の条件下では式 (13), (14)の関係は $T_{\mathrm{m}}$ においても 近似的に成立つ故上式に式(11)，(13)，(14), (6)を代 入し $Z_{0}=12, \alpha=0.033, \beta=0.0096$ を用いると

$$
\begin{aligned}
\Delta S & =[0.98309+0.28314-0.066-0.31395] N k \\
& =0.8863 N k
\end{aligned}
$$

が得られる。一方, 式(17)から

$$
\Delta S=\frac{\Delta E}{T_{\mathrm{m}}}=0.8851 \mathrm{Nk}
$$

が得られ式(22)とよく一致する.

\section{IV. 結言}

（1） b.c.c. 構造をもつ金属の融解の潜熱，融解のエント ロピーは実験的には同じような温度範囲に融点をもつ f.c.c. 構造の金属のそれよりあ系統的に低い值を取る.

(2) b.c.c. 金属の液体について実験的に得られた隣接原 子間の平均距離は，含まれる空孔の体積を除いた液体のモ ル体積を原子が最密充填配列していると仮定して計算され た隣接原子間距離と非常によく一致することから, b.c.c. 金属の液体においても f.c.c. 金属の液体と全く同じような 無秩序であるが最密充填に近い原子の配列分布を取ると考 えられる。

（3）上記の事実に対し, b.c.c. 金属は融解に際して遷移 過程として f.c.c. 構造の状態を経由して無秩序な原子分布 の液体になると考えることができ，したがって b.c.c. 金 属は融解に際しb.c.c. 構造から遷移状態への転移熱が融解 熱の一部として寄与するととになり, f.c.c. 構造の金属よ り低い融解熱を与える.

(4) b.c.c. 金属の液体状態でのエントロピーは当然 f.c.c. 金属の液体状態でのそれと全く同じになるが，融点 $T_{\mathrm{m}}$ に おける固体状態でのエントロピーは上記の転移熱に由来す る熱的エントロピーの部分だけ増大する故, 融解に伴うエ ントロピー変化はそれだけ減少することが定量的に示され る.

\section{文献}

(1) S.Takeuchi and H.Hayasaka : Trans. JIM, 27 (1986), 923.

（2）竹内 栄: 日本金属学会誌, 52(1988), 1031. 